\title{
Avaliação de Três Cultivares de Panicum maximum Jacq. sob Pastejo: Disponibilidade de Forra- gem, Altura do Resíduo Pós-Pastejo e Participação de Folhas, Colmos e Material Morto 1
}

\author{
Patrícia Amarante Brâncioㄹ, Valéria Pacheco Batista Euclides ${ }^{3}$, Domicio do Nascimento \\ Júnior $^{4}$, Dilermando Miranda da Fonseca ${ }^{4}$, Roberto Giolo de Almeida ${ }^{5}$, Manuel Cláudio Motta \\ Macedo ${ }^{3}$, Rodrigo Amorim Barbosa ${ }^{6}$
}

\begin{abstract}
RESUMO - Três cultivares de Panicum maximum Jacq. submetidos a pastejo rotativo foram avaliados ao longo do ano, antes e após o período de pastejo, quanto às disponibilidades de matéria seca total e de folhas, altura, profundidade pastejada, densidade, participações de folhas, colmos e material morto, relações folha/colmo e folha/material morto. Os tratamentos constituíram em: 1) cv. Tanzânia + $50 \mathrm{~kg} / \mathrm{ha} \mathrm{de} \mathrm{N,} \mathrm{2)} \mathrm{cv.} \mathrm{Tanzânia}+100 \mathrm{~kg} / \mathrm{ha} \mathrm{de} \mathrm{N,} \mathrm{3)} \mathrm{cv.} \mathrm{Mombaça}+50 \mathrm{~kg} / \mathrm{ha} \mathrm{de} \mathrm{B} \mathrm{e} \mathrm{4)} \mathrm{cv.} \mathrm{Massai} \mathrm{+} \mathrm{N} 50 \mathrm{~kg} / \mathrm{ha}$ de N. O cultivar Mombaça apresentou menores disponibilidades de folhas, e maiores proporções de colmo, enquanto o cv. Massai tanto apresentou características que poderiam favorecer a seleção de folhas, como maior densidade de MS e maior relação folha/colmo, como a característica desfavorável de apresentar menor relação folha/material morto. No cv. Tanzânia, a adubação nitrogenada no final do período chuvoso trouxe benefícios apenas em março, quando houve aumento nas relações folha/colmo e folha/material morto. A profundidade pastejada correlacionou-se positivamente com a altura, e os animais pastejaram em média $41 \%$ da altura da pastagem, no período seco, e $47 \%$ no período chuvoso.
\end{abstract}

Palavras-chave: características quantitativas, disponibilidade, pastejo rotativo, relação folha/colmo

\section{Evaluation of Three Cultivars of Panicum maximum Jacq. under Grazing: Forage Availability, Post Grazed Stubble Height and Participation of Leaves, Stems, and Dead Material}

\begin{abstract}
Three cultivars of Panicum maximum Jacq. under rotational grazing were evaluated for one year, before and after grazing, when measurements were made of the availability of total dry matter, height, residual dry matter, forage density, leaf dry matter, participation of leaves, stems and dead material, and ratios of leaf:stem and leaf:dead plant material. The treatments were 1) v. Tanzania $+50 \mathrm{~kg} \mathrm{~N} / \mathrm{ha}, 2) \mathrm{v}$. Tanzania $+100 \mathrm{~kg} \mathrm{~N} / \mathrm{ha}$, 3) v. Mombaça $+50 \mathrm{~kg} \mathrm{~N} / \mathrm{ha}$, and 4) v. Massai $+50 \mathrm{~kg} \mathrm{~N} / \mathrm{ha}$. The Mombaça cultivar presented the poorest results, lowest production of leaves and the highest proportion of stems. However, the cv. Massai deservers attention for characteristics such as higher density of DM and higher leaf lamina:stem ratio; however, it presented a lower ratio of leaves:dead material. There were no significant differences in percentage of leaves among the cultivars. In the cv. Tanzania, nitrogen fertilization at the end of the rainy period had beneficial effects only in March when there was an increase in the leaf:stem and leaf:dead plant material ratios. The residual dry matter correlated positively with the height of the forage. The animals grazed $41 \%$ of the height of the pasture in the dry period, and $47 \%$ in the rainy period.
\end{abstract}

Key Words: leaf:stem ratio, leaves available, pasture rotation, quantitative characteristics

\section{Introdução}

O uso de pastagens como principal fonte de alimento para produção de ruminantes é altamente recomendável, pois as condições ambientais contribuem para um menor custo da forragem. As pastagens atendem às exigências nutricionais de algumas categorias animais, quando as condições de umidade e temperatura são favoráveis. No entanto, no período da seca, ocorre a queda na qualidade da forragem, devido à redução do teor de proteína e digestibilidade (Brâncio et al., 1997) e à rápida lignificação das gramíneas (Silva \& Silva, 1976), comprometendo a produção animal.

Ademais, o comportamento das gramíneas tropicais é estacional com maiores taxas de crescimento no período de maior precipitação e temperaturas médias mínimas acima de $25-30^{\circ} \mathrm{C}$ (Pedreira \& Mattos, 1981) e não existe uma espécie capaz de permanecer com alta produção durante o período seco. Entretan-

\footnotetext{
${ }^{1}$ Parte da tese (Doutorado - Zootecnia) do primeiro autor junto à UFV. Pesquisa financiada pela EMBRAPA - Gado de Corte, CAPES e CNPq.

2 Doutora em Zootecnia - UFV. Email: pbrancio@zipmail.com.br

3 Pesquisadores da EMBRAPA - Gado de Corte, Caixa postal 154, CEP 79002-970, Campo Grande, MS.

4 Professores do Departamento de Zootecnia da UFV, CEP 36571-000, Viçosa - MG.

5 Professor do Departamento de Agronomia da UNEMAT, Tangará da Serra, MT, 78300-000. E.mail: robertogiolo@unemat.br

6 Estudante de Doutorado em Zootecnia da UFV, CEP 36571-000, Viçosa - MG.
} 
to, é necessário desenvolver novas opções forrageiras que venham a apresentar melhores distribuições estacionais, em termos qualitativos e quantitativos.

Além da introdução de espécies forrageiras que apresentam melhor distribuição estacional na sua produção, outra opção viável para melhorar a utilização das pastagens durante o período crítico e, conseqüentemente, aumentar as oportunidades para a produtividade animal consiste na adubação nitrogenada no final do período das chuvas (Werner, 1986; Euclides, 1996). No entanto, observa-se, em geral, aumentos na capacidade de suporte das pastagens adubadas com nitrogênio, porém a produção por animal parece ser pouco afetada por esta prática.

Com essas propostas, foram avaliados 156 acessos de Panicum maximum Jacq. na EMBRAPA Gado de Corte, sendo os 25 melhores submetidos a uma Rede de Ensaios Regionais, de onde foram selecionados os setes melhores, tendo como parâmetro o capim-colonião, bastante utilizado em criações de gado de corte, por promover ganhos de peso por animal e por área adequados, porém não tolerante à baixa fertilidade do solo e à seca. Entre os acessos avaliados, os mais promissores foram o Tanzânia, o Mombaça e o Massai.

Segundo Santos (1997), o conhecimento das diversas características da vegetação fornece informações necessárias para promover seu eficiente aproveitamento e auxilia no manejo de pastagens, para garantir $o$ atendimento das exigências de mantença e produção dos animais. Portanto, o primeiro passo no manejo de pastagens consiste em conhecer as características da pastagem, para assim direcionar as tomadas de decisão. Disponibilidade de forragem, altura, densidade e composição botânica são características do pasto usualmente mensuradas e propiciam as informações básicas do quanto e de que forma a forragem está disponível, embora amostragens estratificadas contribuam mais para detalhar o perfil da pastagem. As participações dos componentes folha, colmo e material morto na pastagem têm sido estimadas por meio da separação manual de amostras colhidas no campo, e são importantes na caracterização da massa de forragem, pois, além de apresentarem composição química e digestibilidade características, a proporção destes componentes pode influenciar a apreensão de forragem pelos animais (Torregroza Sanchez et al., 1993; Santos, 1997).

A estrutura da pastagem é um fator importante na determinação da facilidade com que a forragem é apreendida pelo animal. É possível observar que diferentes níveis de ingestão podem ser atingidos, por exemplo, numa mesma quantidade de massa de forragem disponível. Isto acontece porque, na verdade, uma mesma massa de forragem pode se apresentar ao animal de diferentes formas através de inúmeras combinações entre altura e densidade (Carvalho, 1997).

À medida que os animais selecionam as partes mais palatáveis das plantas, em geral as folhas verdes, a pastagem apresenta proporção crescente de material não preferido ou recusado, como colmos e material morto, ao longo do período de ocupação, dificultando cada vez mais a seleção e a ingestão de forragem.

Assim, realizou-se um estudo sobre as características quantitativas de pastagens dos cultivares de Panicum maximum Jacq. Tanzânia (com dois níveis de adubação), Mombaça e Massai, submetidos a pastejo rotativo, antes da entrada e após a saída dos animais.

\section{Material e Métodos}

O trabalho foi realizado em uma área pertencente à Embrapa Gado de Corte, localizada em Campo Grande, Mato Grosso do Sul. O solo desta área foi classificado como Latossolo Vermelho Escuro álico, caracterizado por textura argilosa, $\mathrm{pH}$ ácido, baixa saturação de bases e alta concentração de alumínio.

A região é caracterizada por temperaturas máximas médias que variam de $25^{\circ}$ a $33^{\circ} \mathrm{C}$ e temperaturas mínimas médias de $14^{\circ}$ a $22^{\circ} \mathrm{C}$. A precipitação pluviométrica anual é de aproximadamente $1.400 \mathrm{~mm}$, caracterizada por uma distribuição estacional, pois em torno de $78 \%$ das chuvas ocorrem entre os meses de outubro e março.

Para implantação das pastagens, em 1993, a área foi limpa e gradeada, e foi realizada uma calagem, aplicando-se 2,7 t/ha de calcário dolomítico. Em janeiro de 1994, em todos os tratamentos, realizou-se uma adubação com $500 \mathrm{~kg} / \mathrm{ha}$ de NPK 0-20-15 e $50 \mathrm{~kg} / \mathrm{ha}$ de FTE BR-12 anterior a semeadura, e em maio desse mesmo ano, efetuou-se uma adubação com $500 \mathrm{~kg} /$ ha de NPK 20-0-20. Em janeiro de 1995 foi realizada uma adubação com $110 \mathrm{~kg} /$ ha de uréia e, a partir deste ano, de outubro a novembro, todos os tratamentos receberam adubação de manutenção em fósforo e potássio, com $200 \mathrm{~kg} / \mathrm{ha}$ de 0-20-20, e em nitrogênio, com $250 \mathrm{~kg} /$ ha de sulfato de amônio (1996 e 1997) ou $110 \mathrm{~kg} /$ ha de uréia (1998). O tratamento Tanzânia + 100 kg/ha de $\mathrm{N}$ recebeu, além da adubação de manutenção comum a todos os tratamentos, 
uma adubação adicional de $50 \mathrm{~kg} / \mathrm{ha}$ de nitrogênio no final do período chuvoso, sendo que em 1995 e 1999 utilizou-se $250 \mathrm{~kg} / \mathrm{ha}$ de sulfato de amônio, enquanto em 1996, 1997 e 1998 utilizou-se $110 \mathrm{~kg} /$ ha de uréia.

Os quatro tratamentos foram constituídos dos cultivares de Panicum maximum Jacq.: 1 - cv. Tanzânia (50 kg/ha de N); 2 - cv. Tanzânia com adubação nitrogenada $(50 \mathrm{~kg} / \mathrm{ha}$ de $\mathrm{N})$ adicional à de manutenção, totalizando $100 \mathrm{~kg} / \mathrm{ha}$ de N; 3 - cv. Mombaça (50 kg/ha de N); e 4 - cv. Massai (50 kg/ha de N).

As amostragens foram realizadas em junho, setembro e novembro de 1998 e março de 1999, que representaram meados e fim da época seca e início e final da época chuvosa. Utilizou-se uma área total de 6 ha, dividida em quatro piquetes de 1,5 ha (um por tratamento), submetidos a pastejo rotativo, sendo cada piquete subdividido em seis áreas de $0,25 \mathrm{ha}, \mathrm{o}$ que permitiu um ciclo de pastejo de 42 dias, com sete dias de utilização e 35 dias de descanso. Cada piquete foi pastejado por quatro bovinos (animais-teste), com peso médio inicial de aproximadamente $150 \mathrm{~kg}$, e animais adicionais, que foram colocados ou removidos de acordo com a disponibilidade de forragem, para que houvesse um resíduo total após o pastejo de cerca de 2,0 a $2,5 \mathrm{t} /$ ha de matéria seca.

\section{Amostragem na pastagem}

Em cada mês de amostragem, foram avaliadas três áreas de 0,25 ha em semanas consecutivas, para cada piquete ou tratamento. Para caracterização das pastagens, a disponibilidade de forragem, a altura, a densidade de matéria seca, e as proporções de folha, colmo e material morto foram estimadas para todos os tratamentos nas épocas de avaliação, antes da entrada e após a saída dos animais nos piquetes.

A disponibilidade de matéria seca total foi estimada cortando-se a forragem em 15 quadrados $\left(1 \mathrm{~m}^{2}\right)$, ao nível do solo, alocados ao acaso. As amostras foram divididas em duas partes, sendo uma secada em estufa a $65^{\circ} \mathrm{C}$ e pesada para se estimar a disponibilidade de matéria seca total e a outra utilizada para formar amostras compostas (uma composta a cada cinco amostras). As amostras compostas foram separadas manualmente em lâmina foliar (a partir da lígula), pseudocolmo (colmo e bainhas), material morto e inflorescência, sendo secada em estufa a $65^{\circ} \mathrm{C}$, pesada e moída.

A altura das plantas foi determinada com o uso de uma régua, nos mesmos quadrados que foram utilizados para estimar a disponibilidade de matéria seca total, sendo a altura média das plantas (em cada quadrado amostrado) determinada pela média da altura de quatro pontos aleatórios dentro desse.

A densidade de matéria seca consistiu na divisão da disponibilidade de matéria seca total por área pela altura média das plantas $(\mathrm{kg} / \mathrm{ha} / \mathrm{cm})$.

\section{Análises estatísticas}

Para os dados em questão, considerando "I" tratamentos (ou cultivares) e "p" meses (medidas repetidas no tempo), foi utilizada a Análise Multivariada com Medidas Repetidas, indicada quando há um ou mais de um fator com medidas repetidas. Utilizou-se o programa SAS (1990) para realização de todos os procedimentos de análise estatística.

A primeira hipótese de interesse foi a de paralelismo, que corresponde à hipótese de que não há efeito da interação tratamentos $\mathrm{x}$ meses, e foi avaliada pelo teste de Wilks, adotando-se o nível de significância de 5\%.

Quando a hipótese de paralelismo foi rejeitada, adotou-se o seguinte procedimento:

1 - Avaliaram-se separadamente os tratamentos para cada mês, por meio de análise de variância univariada por mês, em que se testou a hipótese de igualdade de médias de tratamento. Em caso de rejeição de $\mathrm{H}_{0}$, comparam-se as médias de tratamento pelo teste Tukey a $5 \%$ de probabilidade.

2 - Avaliou-se separadamente o efeito dos meses dentro de cada tratamento, por meio de análise descritiva.

Quando a hipótese de paralelismo não foi rejeita$\mathrm{da}$, adotou-se o seguinte procedimento:

1 - Testou-se a hipótese de igualdade das médias de tratamentos, independentemente dos diferentes meses medidos. Quando a hipótese $\mathrm{H}_{0}$ foi rejeitada, as médias de tratamento foram comparadas pelo teste Tukey em nível de significância de 5\%.

2 - Testou-se a hipótese de igualdade das médias de meses pelo teste de Wilks, adotando-se o nível de $5 \%$ de significância.

\section{Resultados e Discussão}

A disponibilidade de matéria seca total variou de aproximadamente 2.000 a $5.000 \mathrm{~kg} / \mathrm{ha}$ ao longo do ano (Figura 1a). Em termos médios, a disponibilidade concorda com Gerdes et al. (1998) que relataram $2.920 \mathrm{~kg} / \mathrm{ha}$ de MS em pastagem do cv. Tanzânia, após 35 dias do corte, enquanto Correa et al. (1998) 
verificaram disponibilidades de 3.300 e $4.000 \mathrm{~kg} / \mathrm{ha}$ de MS em pastagens do cv. Tanzânia e cv. Massai, respectivamente. Para o cv. Mombaça, estes autores observaram um valor de $3.600 \mathrm{~kg} / \mathrm{ha}$ de MS, após 35 dias de crescimento.

No momento da entrada dos animais nos piquetes, observou-se que a disponibilidade de matéria seca total (DMS) no cv. Mombaça foi sempre inferior aos demais $(\mathrm{P}<0,05)$, independentemente da época de avaliação, indicando maior exigência em fertilidade deste cultivar. O manejo adotado com período de descanso de 35 dias e adubação de manutenção de $50 \mathrm{~kg} / \mathrm{ha}$ de $\mathrm{N}$ não foi adequado para que ele expressasse altas produções de matéria seca. Assim, foi colocado menor quantidade de animais neste cultivar, para que após os 7 dias de utilização houvesse um resíduo de no mínimo 2,0 t/ha de MS. Entretanto, valores inferiores ao resíduo esperado foram encontrados neste cultivar (Figura 1b). Por

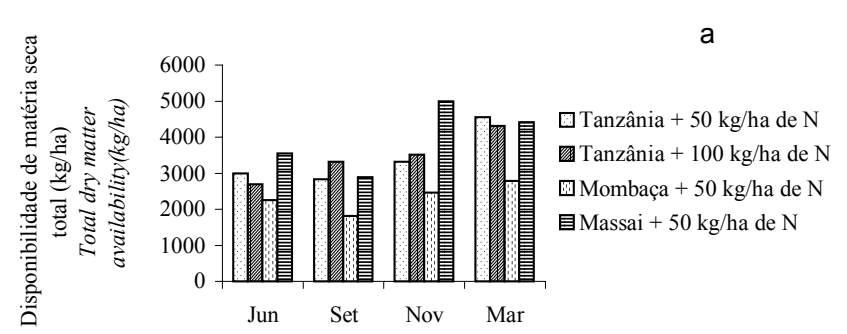

b

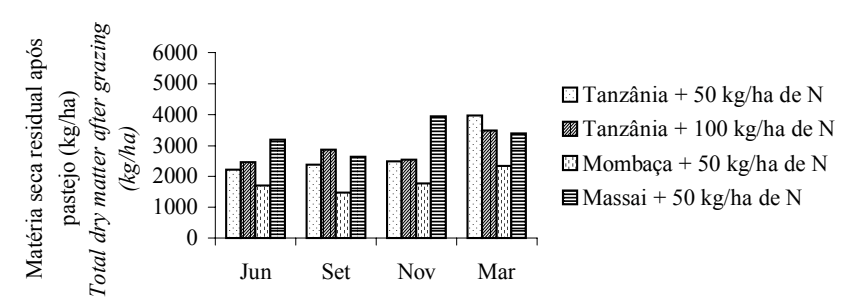

Figura 1 - Matéria seca total antes (a) e após o pastejo (b) por bovinos em pastagens de cultivares de Panicum maximum Jacq. em junho, setembro e novembro de 1998 e março de 1999.

Figure 1 - Total dry matter before (a) and after grazing in pastures of Panicum maximum Jacq. cultivars in June, September and November of 1998 and March of 1999.

R. Bras. Zootec., v.32, n.1, p.55-63, 2003 outro lado, não houve disponibilidades inferiores a 1,0 $\mathrm{t} /$ ha de MS, considerada como crítica, abaixo da qual os animais teriam dificuldade em colher forragem (Minson, 1983). Entretanto, este valor deve ser considerado com cautela, pois as proporções de folhas, colmos e material morto e a sua distribuição ao longo do perfil da pastagem têm maior influência sob o comportamento ingestivo dos animais.

Os cultivares Tanzânia e Massai não diferiram entre si $(\mathrm{P}>0,05)$ quanto a disponibilidade de matéria seca total, tanto antes como depois do pastejo. Apesar da tentativa em manter os resíduos de 2,0 a 2,5 t/ha de MS por meio de estimativas visuais e alterando as taxas de lotação, estes ficaram próximos a 3,0 t/ha.

O cultivar Massai, de porte mais baixo, apresentou altura média antes do pastejo, inferior apenas ao cultivar Tanzânia $+50 \mathrm{~kg} / \mathrm{ha}$ de N (Figura 2a), enquanto os demais tratamentos não diferiram entre si. Após o pastejo (Figura 2b), não houve diferença

a

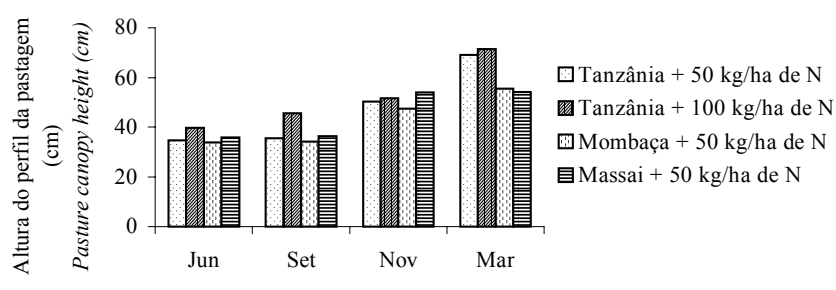

b

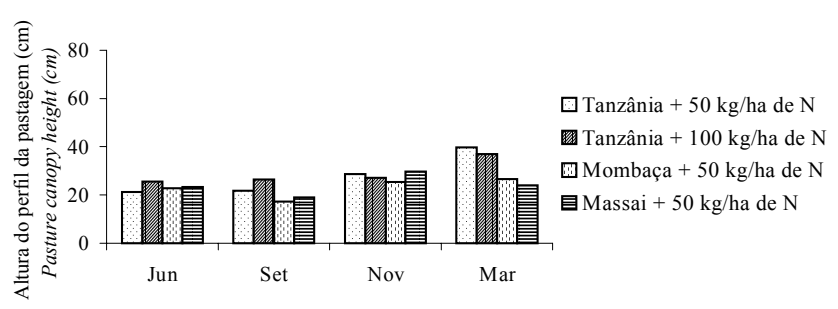

Figura 2 - Altura do perfil da pastagem antes (a) e após (b) o pastejo por bovinos em pastagens de cultivares de Panicum maximum Jacq. em junho, setembro e novembro de 1998 e março de 1999.

Figure 2 - Pasture canopy height before (a) and after grazing in pastures of Panicum maximum Jacq. cultivars in June, September and November of 1998 and March of 1999. 
entre os cultivares $(\mathrm{P}>0,05)$, que apresentaram alturas entre 15 a $30 \mathrm{~cm}$. Observou-se em março, tendência a maiores alturas e disponibilidades residuais, com exceção do cv. Mombaça, indicando que os piquetes poderiam ter sido mais utilizados, com melhores ajustes de lotação.

Dann (1966) relatou correlações bastante altas entre altura e disponibilidade de forragem; mas neste experimento foi verificado o valor de $\mathrm{r}=0,70$. Isto se deveu ao fato do cv. Massai $+50 \mathrm{~kg} / \mathrm{ha}$ de $\mathrm{N}$, de menor porte, ser mais denso em relação aos cvs. Mombaça $+50 \mathrm{~kg} / \mathrm{ha}$ de N e Tanzânia $+100 \mathrm{~kg} / \mathrm{ha}$ de $\mathrm{N}$, conforme apresentado na Figura 3a. Verificou-se também que a densidade no cv. Tanzânia $+50 \mathrm{~kg} / \mathrm{ha}$ de $\mathrm{N}$ foi também superior ao cv. Mombaça $+50 \mathrm{~kg} / \mathrm{ha}$ de N. Após o pastejo (Figura 3b), o cv. Massai permaneceu com maiores densidades em relação aos demais, enquanto o cv. Mombaça apresentou os menores valores. Verificaram-se valores intermediários no cv. Tanzânia com os dois níveis de adubação.
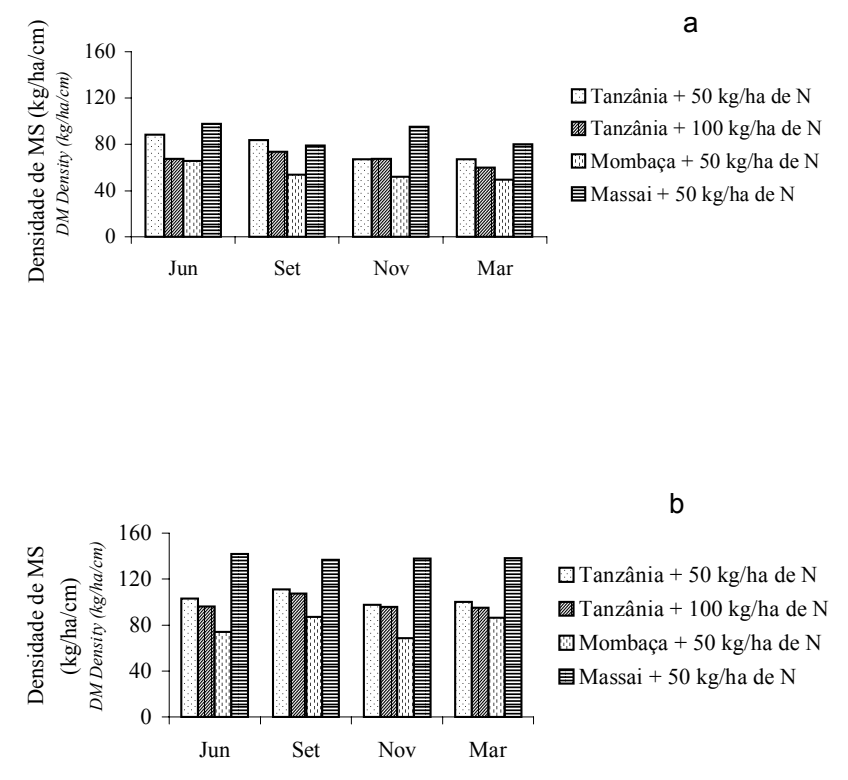

Figura 3 - Densidade de matéria seca antes (a) e após o pastejo (b) por bovinos em pastagens de cultivares de Panicum maximum Jacq. em junho, setembro e novembro de 1998 e março de 1999.

Figure 3 - Dry matter density before (a) and after grazing in pastures of Panicum maximum Jacq. cultivars in June, September and November of 1998 and March of 1999.
Analisando a altura do resíduo após pastejo (Figura 4), verificou-se que os animais pastejaram uma camada do perfil da pastagem proporcional à altura que havia antes do período de pastejo $(r=0,99)$, independente da espécie. Esta correlação encontrada está de acordo com os estudos de Laca et al. (1992), nos quais a profundidade de bocado variou linearmente com a altura, e de Burlison et al. (1991), que encontraram correlação de 0,96 entre altura e profundidade de bocado. Entretanto, vale ressaltar que uma maior profundidade pastejada não significa necessariamente maior profundidade por bocado, pois os animais permaneceram vários dias pastejando no mesmo piquete e todos os perfilhos foram, provavelmente, pastejados mais de uma vez.

Segundo Roguet et al. (1998), os animais tendem a explorar a estação de pastejo ou estação alimentar, que foi definida em Carvalho et al. (1999) como uma área hipotética disponível ao animal, a qual ele alcançaria sem mover as suas patas dianteiras, por estratos, especialmente em perfis mais altos. Isto pôde ser observado neste experimento, pois no segundo dia de ocupação dos piquetes pelos animais a maioria das pontas das folhas estava colhida.

Verificou-se que os animais pastejaram, em média, $41 \%$ da altura da pastagem, no período seco, enquanto este valor foi de $47 \%$ no período chuvoso. O resíduo após pastejo pode estar associado à camada de folhas ou, ainda, à barreira formada por material morto e às bainhas das folhas na parte basal da planta. Alguns estudos sugerem que os colmos sejam

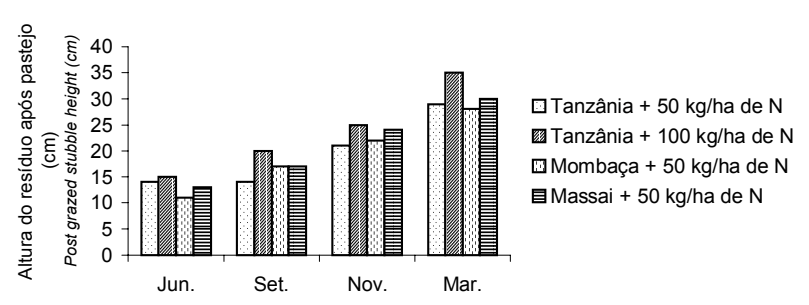

Figura 4 - Altura do resíduo após pastejo por bovinos em pastagens de cultivares de Panicum maximum Jacq. em junho, setembro e novembro de 1998 e março de 1999.

Figure 4 - Post grazed stubble height of pastures of Panicum maximum Jacq. cultivars in June, September and November of 1998 and March of 1999.

R. Bras. Zootec., v.32, n.1, p.55-63, 2003 
barreira para obtenção de pastejos mais profundos, devido à maior força requerida na sua colheita, mas isto não tem sido confirmado (Laca \& Ungar, 1992).

Não houve interação entre os fatores cultivar e mês de avaliação nas variáveis: percentagem de folhas, de colmos e de material morto, com exceção desta última variável, após o período de passtejo (Tabelas 1 e 2). Assim, independentemente da época, não houve diferenças significativas entre as participações médias de folhas na forragem disponível nos cultivares estudados, tanto antes como após o período de pastejo. O cv. Massai apresentou menores participações de colmos $(\mathrm{P}<0,05)$, antes e após o período de pastejo, enquanto o cv. Mombaça foi o que apresentou $(\mathrm{P}<0,05)$ mais material estrutural.

A participação de material morto no cv. Mombaça antes do período de pastejo foi menor, embora não tenha diferido $(\mathrm{P}>0,05)$ do cv. Tanzânia $+100 \mathrm{~kg} / \mathrm{ha}$ de $\mathrm{N}$, que foi semelhante aos demais $(\mathrm{P}>0,05)$. Após o período de pastejo, observaram-se diferenças entre tratamentos apenas em setembro de 1998 e março de 1999, com tendência a maiores valores no cv. Massai.

Avaliando o efeito do mês de amostragem nas frações da planta (Tabelas 1 e 2), observou-se que a participação de folhas e de colmos foi maior no final do período chuvoso (março de 1999), quando o crescimento das plantas é intenso, havendo alta produção de folhas, mas também maior alongamento de colmos. Neste período, a participação de material morto decresceu. No período seco, a quantidade de material morto representou cerca da metade do total de forragem disponível, o que indica uma possível restrição ao consumo de forragem, em termos de acessibilidade de folhas verdes. Em termos de disponibilidade de folhas verdes, acredita-se que não houve restrições ao consumo de matéria seca em nenhum período, pois as estimativas de disponibilidade de folhas foram sempre próximas ou superiores a $800 \mathrm{~kg} / \mathrm{ha}$ (Figura 5a) antes da entrada dos animais, independente do tratamento. Entre os tratamentos, observou-se tendência à maior disponibilidade de folhas na cv. Massai em junho e novembro, e tendência a menor disponibilidade de folhas na cv. Mombaça em setembro e novembro de 1998 e março de 1999. Após o período de pastejo (Figura 5b), verificou-se que a disponibilidade de folhas foi de 41 a $75 \%$ menor em relação àquela antes do pastejo, dependendo do tratamento e do mês de amostragem. Isto indica que houve consumo pre-

Tabela 1 - Porcentagens de folhas, colmos e material morto em pastagens de cultivares de Panicum maximum Jacq., em junho, setembro e novembro de 1998 e março de 1999, antes da entrada dos animais nos piquetes

Table 1 - Percentages of leaf, stem and dead plant material in pastures of Panicum maximum Jacq. cultivars, in June, September and November of 1998 and March of 1999, before paddocks grazing

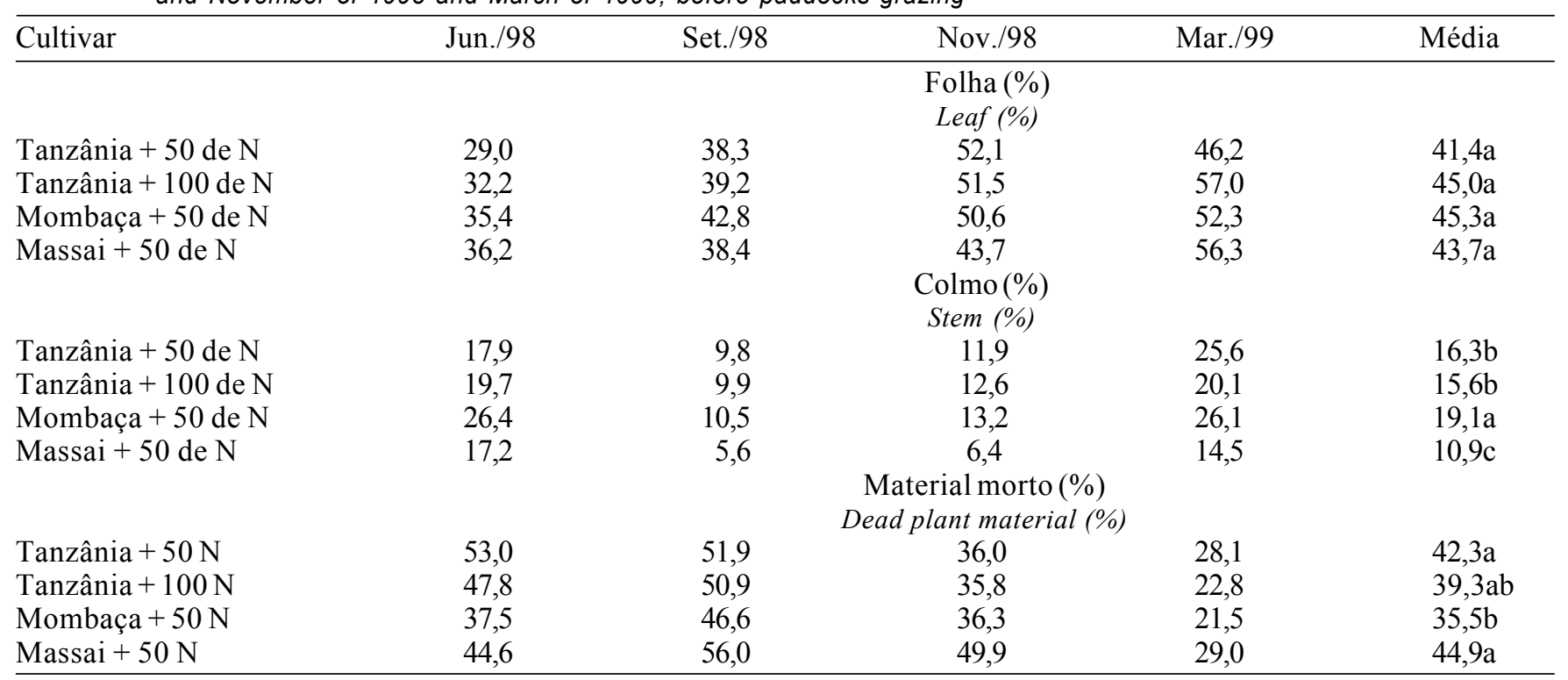

Médias seguidas de pelo menos uma mesma letra, na mesma coluna, não diferiram entre si pelo teste Tukey (P>0,05).

Mean values followed by different letter are not different by Tukey test $(P>.05)$.

R. Bras. Zootec., v.32, n.1, p.55-63, 2003 
Tabela 2 - Porcentagens de folhas, colmos e material morto em pastagens de cultivares de Panicum maximum Jacq., em junho, setembro e novembro de 1998 e março de 1999, após a saída dos animais dos piquetes

Table 2 - Percentages of leaf, stem and dead plant material in pastures of Panicum maximum Jacq. cultivars, in June, September and November of 1998 and March of 1999, after grazing

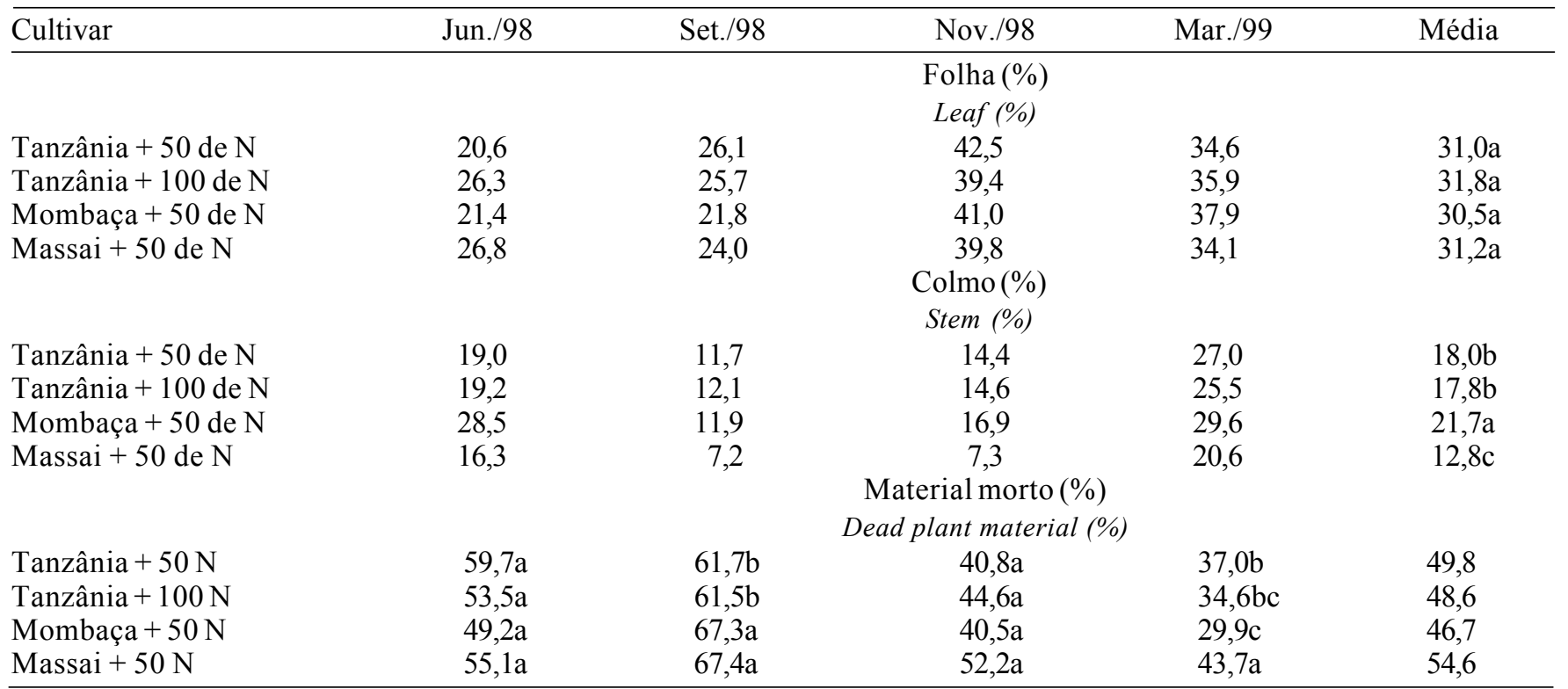

Médias seguidas de pelo menos uma mesma letra, na mesma coluna, não diferiram entre si pelo teste Tukey $(P>0,05)$. Mean values followed by different letters are not different by Tukey test $(P>05)$.
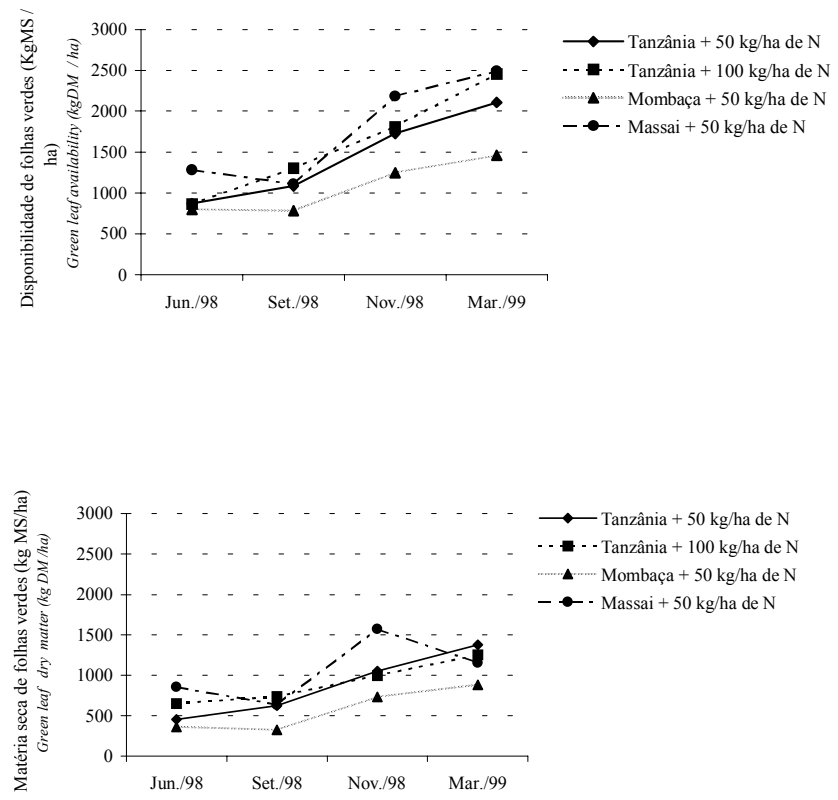

Figura 5 - Matéria seca de folhas verdes (kg MS/ha) antes (a) e após (b) o período de pastejo por bovinos em pastagens de cultivares de Panicum maximum Jacq., em junho, setembro e novembro de 1998 e março de 1999.

Figure 5 - Green leaf dry matter (kg DM /ha) before (a) and after (b) grazing in pastures of Panicum maximum Jacq. cultivars in June, September and November of 1998 and March of 1999. ferencial desta parte da planta pelos animais, mas que não houve restrição ao consumo, em termos de quantidade. O consumo preferencial por folhas pôde ser indicado também pela redução na percentagem de folhas e aumento na percentagem de colmos durante o período de pastejo (Tabelas 1 e 2).

A relação lâmina/colmo é uma variável de grande importância para a nutrição animal e para o manejo da plantas forrageiras (Wilson, 1982), devido ao fato desta estar associada à facilidade com que os animais colhem a forragem preferida (folhas). Tem-se considerado um limite crítico para esta relação de 1,0 (Pinto et al., 1994), sendo que valores inferiores a este implicariam queda na quantidade e qualidade de forragem produzida. Neste estudo, os valores encontrados foram sempre superiores a 1,0 apresentando valores próximos a 4,0 no final do período seco e início do período chuvoso (Figura 6). As relações lâmina/colmo foram semelhantes nos cultivares Tanzânia (com 50 e 100 kg/ha de N) e Mombaça, enquanto no cv. Massai houve maior relação lâmina / colmo em relação aos demais, chegando a valores próximos de 7,0, provavelmente devido ao menor peso dos colmos, o que indicaria condições favoráveis para seleção de folhas pelos bovinos. Por outro lado, este cultivar apresentou tendência a menor relação lâmina/ material morto no período chuvoso (Figura 7), o que

R. Bras. Zootec., v.32, n.1, p.55-63, 2003 


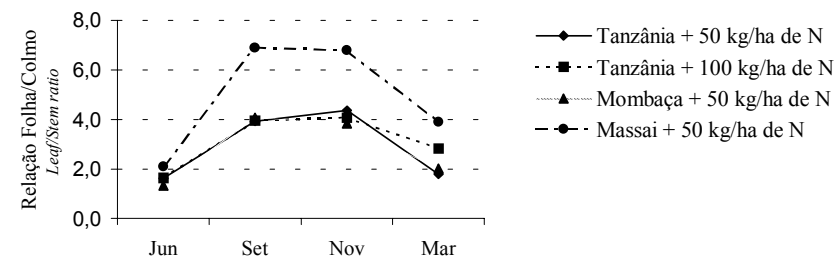

Figure 6 - Relação folha/colmo em pastagens de cultivares de Panicum maximum Jacq. em junho, setembro e novembro de 1998 e março de 1999.

Figure 6 - Leaf/stem ratio in pastures of Panicum maximum Jacq. cultivars in June, September and November of 1998 and March of 1999.

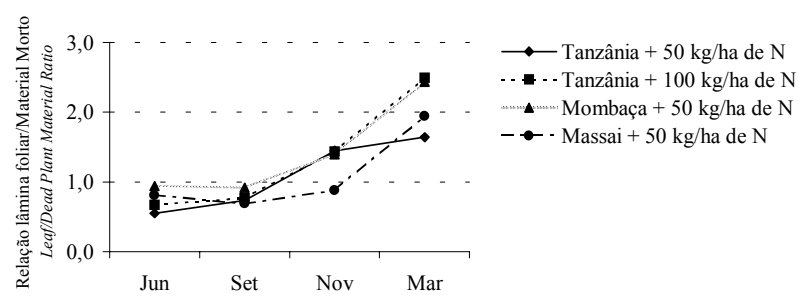

Figura 7 - Relação lâmina foliar/material morto em pastagens de cultivares de Panicum maximum Jacq. em junho, setembro e novembro de 1998 e março de 1999.

Figure 7 - Leaf/Dead plant material ratio in pastures of Panicum maximum Jacq. cultivars in June, September and November of 1998 and March of 1999.

pode ser indicativo de um fluxo de tecidos mais rápido.

Os valores referentes a relação folha/colmo aqui encontrados para os cvs.Tanzânia e Mombaça foram bastante superiores aos relatados por Santos (1997), que apresentou valores entre 1,0 e 2,0 no período de novembro a abril, e valores abaixo de 1,0 no período de abril a maio.

No início do período chuvoso, os animais teriam melhores condições para seleção de folhas, pois a estrutura da pastagem seria mais favorável, com as maiores relações folha/colmo e folha/material morto. Já no final do período chuvoso (março), apesar da alta relação folha/material morto, houve baixa relação folha/ caule, em conseqüência do alongamento dos colmos.

Ao estudar o efeito da adubação nitrogenada realizada no final do período chuvoso no cv. Tanzânia, observou-se que não houve ganhos significativos na disponibilidade de matéria seca total, conforme relatado na literatura.

Também não foram encontradas diferenças quanto à altura antes e após pastejo e a participação de folhas, colmos e material morto. Entretanto, em março, foi verificada tendência a maiores relações folha/ colmo e folha/material morto, que pode constituir um benefício para os animais em pastejo.

\section{Conclusões}

O cv. Mombaça apresentou menores disponibilidades de folhas e maiores proporções de colmo.

O cultivar Massai apresentou maiores densidade e relação folha/colmo, entretanto, foi observada menor relação folha/material morto.

No cv. Tanzânia, a adubação nitrogenada no final do período chuvoso trouxe benefícios apenas em março, quanto às relações folha/colmo e folha/material morto.

A profundidade pastejada correlacionou-se positivamente com a altura, e os animais pastejaram, em média, 41 e $47 \%$ da altura das plantas, nos períodos seco e chuvoso, respectivamente.

\section{Literatura Citada}

BRÂNCIO, P.A.; NASCIMENTO Jr., D.; MORAES, E.A. et al. Avaliação de pastagem nativa dos cerrados submetida à queima anual. 2. qualidade da dieta de bovinos. Revista Brasileira de Zootecnia, v.26, p.3, p.438-442, 1997.

BURLISON, A.J.; HODGSON, J.; ILLIUS, A.W. Sward canopy structure and the bite dimension and bite weight of grazing sheep. Grass and Forage Science, v.46, p.29-38, 1991.

CARVALHO, P.C.F.; PRACHE, S.; DAMASCENO, J.C. O processo de pastejo: desafios da procura e apreensão da forragem pelo herbívoro. In: REUNIÃO ANUAL DA SOCIEDADE BRASILEIRA DE ZOOTECNIA, 37., 1999, Porto Alegre. Anais... Porto Alegre: Sociedade Brasileira de Zootecnia, 1999. p.253-268.

CARVALHO, P.C.F. A estrutura da pastagem e o comportamento ingestivo de ruminantes em pastejo. In: SIMPOSIO SOBRE AVALIAÇÃO DE PASTAGENS COM ANIMAIS, 1997, Maringá. Anais... Maringá: Universidade Estadual de Maringá, 1997. p.25-52.

CORREA, L.A., FREITAS, A.R., BATISTA, L.A. Níveis de nitrogênio e freqüências de corte em 12 gramíneas forrageiras tropicais. 1. Produção de matéria seca. In: REUNIÃO ANUAL DA SOCIEDADE BRASILEIRA DE ZOOTECNIA, 35., 1998. Anais... Botucatu: Sociedade Brasileira de Zootecnia, 1998. v.2, p.304-306. 
DANN, P.R. A calibration method for estimating pasture yield. Journal Australian Institute of Agricultural Science, v.32, n.1, p.46-49, 1966 .

EUCLIDES, V.P.B. Técnicas de implantação, manejo e utilização de pastagens visando ao aumento de produtividade de bovídeos. Campo Grande: EMBRAPA/ CNPGC, 1996. 9p.

GERDES, L.A.; WERNER, J.C.; FERREIRA, T.A. et al. Produção de matéria seca e algumas características morfológicas de três capins em três idades de corte. In: REUNIÃO ANUAL DA SOCIEDADE BRASILEIRA DE ZOOTECNIA, 35., 1998, Botucatu. Anais... Botucatu: Sociedade Brasileira de Zootecnia, 1998. v.2, p.263-265.

LACA, E.A.; UNGAR, E.D.; SELEGMAN, N.G. et al. An integrated methodology for studying short-term grazing behavior of cattle. Grass and Forage Science, v.47, p.8190, 1992.

LACA, E.A.; UNGAR, E.D. Effects of sward height and bulk density on bite dimensions of cattle grazing homogeneous swards. Grass and Forage Science, v.47, p.91-100, 1992.

(Citar local)MINSON, D.J. Forage quality: assessing the plantanimal complex. INTERNATIONAL GRASSLAND CONGRESS, 14., 1983. Proceedings... 1983, p.23-29.

PEDREIRA, J.V.S.; MATTOS, H.B. Crescimento estacional de vinte e cinco espécies ou variedades de capins. Boletim da Indústria Animal, v.38, n.2, p.117-143, 1981.

PINTO, J.C.; GOMIDE, J.A.; MAESTRI, M. et al. Crescimento de folhas de gramíneas forrageiras tropicais, cultivadas em vasos, com duas doses de nitrogênio. Revista da Sociedade Brasileira de Zootecnia, v.23, n.3, p.327-332, 1994.

ROGUET, C.; PRACHE, S.; PETIT, M. Development of methodology for studying feeding station behavior of grazing ewes. Applied Animal Behavior Science, v.55, p.307-316, 1998.
SANTOS, M.V.F. Métodos agronômicos para estimativa de consumo e disponibilidade de forragem na Zona da Mata, Viçosa - MG. Viçosa, MG: Universidade Federal de Viçosa, 1997. 155p. Tese (Doutorado em Zootecnia) - Universidade Federal de Viçosa, 1997.

SAS INSTITUTE SAS/STAT. User's guide statistics, Versão 6, 4.ed., Cary, NC: 1990. 846p.

SILVA, J.H.S.; SILVA, D.J. Nutritive value of tropical forage in Brazil. In: INTERNATIONAL SIMPOSIUM FEED COMPOSITION, 1., 1976, Logan, Utah. Proceedings... Logan: Utah State University, 1976.

TORREGROZA SANCHEZ, L.J., NASCIMENTO JR., D., DIOGO, J.M.S. et al. Composição botânica da dieta de novilhos esôfago-fistulados em pastagem natural de Viçosa. Revista da Sociedade Brasileira de Zootecnia, v.22, p.5, p.852-861, 1993.

WERNER, J.C. Adubação de pastagens. Nova Odessa: Instituto de Zootecnia, 1986. 49p. (Boletim técnico, 18).

WILSON, J.R. Environmental and nutritional factors affecting herbage quality. In: HACKER, J.B. (Ed.) Nutritional limits to animal production from pastures. Farnham Royal: CAB, 1982. p.111-131. 